\title{
Managerial narratives: a critical dialogical approach to managerial identity
}

\author{
Steve McKenna \\ School of Administrative Studies, Atkinson Faculty, \\ York University, Toronto, Canada
}

\begin{abstract}
Purpose - The purpose of this paper is to explore the use of a dialogical approach, associated with the Russian literary critic and philosopher Bakhtin, in understanding the portrayal of managerial identity in management narratives. In particular, it applies these ideas critically to understand how managers' identities are partly shaped by the dominant discourse or idea about what a manager should "be."

Design/methodology/approach - The paper draws on three written narratives of managers. It applies a dialogical approach to consider how they position themselves interactionally in the narratives in such a way as to highlight a managerial identity based on being "enterprising" and "for change," while simultaneously voicing alternative identities negatively. The use of the written narratives of managers and the application of a dialogical approach is an important contribution to the literature.

Findings - The findings suggest that managers, when reflecting on organizational events through narrative, assume a managerial identity that reflects current dominant discourse about what a manager should "be." In doing so they reject other possible discourses that offer alternatives, not only to managerial "being," but also to what management and organizations might reflect and represent. The paper also, however, recognizes that some managers reject this identity and its implications for organizational activity.

Research limitations/implications - The paper suggests that managerial identity is partly a product of a dominant discursive/ideological formation rather than individual choice. Although managers may reject this interpellation creating an alternative is constrained by the regime of truth that prevails about what management is at any given time. The approach might be considered overly deterministic in its view of managerial identity.

Originality/value - The paper extends the understanding of managerial identity and how it is portrayed through narrative by using a dialogical approach to interpretation.

Keywords Managers, Narratives, Work identity

Paper type Research paper

\section{Introduction}

This paper addresses issues concerning managerial identity through a critical (Alvesson and Willmott, 1996) lens using the ideas of the Russian philosopher and literary theorist Bakhtin $(1981,1984,1995 \mathrm{a}, \mathrm{b})$ as they have in particular been developed by Wortham (2001). The ideas of Bakhtin (1981, 1984, 1995a, b) and tools of analysis developed by Wortham (2001) are used to deconstruct and interrogate the written narratives of managers in relation to managerial identity. Of particular interest is the manner in which managers not only represent themselves in terms of a managerial identity in their narratives, but also how they engage in dialogic and interactional positioning with respect to this identity. In other words, managers construct an identity as a social product of the self-process, and their narratives reflect how they do this in relation to other persons and discourses in the organizational and social world.
\end{abstract}


An important element of the paper is to show how at a given moment in time, the autobiographical selves and identities managers narrate in written texts reflect an identity that they are called to "be" (interpellated to be) (Althusser, 2001) and which is normalized by prevailing and dominant managerial discourse. In their narratives managers position themselves interactionally in relation to an already existing world that holds a certain managerial identity to be "normal." Using Bakhtin (1981, 1984, 1995a, b) and particularly the application of Bakhtin's work by other authors (Wortham, 2001), this paper explores these ideas. In addition, the paper suggests that managerial identity is subject to the pressures of a grand narrative/discourse (Alvesson and Karreman, 2000) that hails managers to assume a particular identity: one that they may or may not accept, and within which narratives are constructed.

\section{Identity}

"Identity" as a topic of research activity continues to flourish (Alvesson et al., 2008). In essence, the study of identity concerns attempts to understand how human actors address the questions of "who they are" and "how to act." There has been some considerable work on professionals and managers, and the identity processes in which they might be engaged, as part of "being" and/or "becoming" a professional and/or manager (Alvesson et al., 2008; Alvesson and Willmott, 2002; Beech, 2008; Musson and Duberley, 2007; Watson, 2008). In the context of putative changes in the nature of organizations and organizing this line of inquiry has become important. In particular it is suggested that the circumstances within which identity is formulated are often ambiguous, discontinuous and paradoxical, and consequently discovering or creating an identity that is secure and stable is difficult if not impossible (Gergen, 1991).

Consequently, individuals need to engage in "identity work" which involves "forming, repairing, maintaining, strengthening or revising the constructions that are productive of a sense of coherence and distinctiveness" (Sveningsson and Alvesson, 2003 , p. 1165). Watson (2008, p. 129) suggests that:

[...]people strive to shape a relatively coherent and distinctive notion of personal self-identity and struggle to come to terms with [...] and influence the various social identities which pertain to them in the various milieu in which they live their lives.

Identity construction, however, is not undertaken in a vacuum, where an individual is striving to discover an "essential self" (Wortham, 2001). Rather it is undertaken dialogically, in contexts with other people, within organizations and in society. Identity is formed in response to what a person might be expected to be as defined by the structures, contexts and discourses within which they operate, and also in how they react to this expectation agentically. In response to societal (structural) and discursive constraints on "being," human actors engage in "internal conversations" (Archer, 2000) about these constraints and expectations and make decisions about the identity they wish to assume.

While identity is formulated by agentic individuals, the structures and discourses within which they live will influence the preferred shape these identities might take. In short, the social construction of identities is subject to influences outside of the individual. As Sarup (1996, p. 54) notes "we become particular individuals acting in the beliefs given to us to think." The poststructuralist Althusser (2001) suggested that individuals are ideologically or through discourses hailed or called to a certain identity. 
They become "what institutional discourses and practices make of them" (Smith and Watson, 2001, p. 43). Foucault (1995) argued that it is through discourse that we are subject to the "normalizing gaze," which serves to make a subject of us. To not submit to this gaze places the subject at the margins of the dominant discourse and to be classified as "abnormal" and having the "wrong" identity. An objective of "normalization" is to create individuals who can self-monitor and self-regulate through "technologies of self," where they perform an identity that constantly (re)constructs a "self" that is acceptable within a dominant discourse (Foucault, 1995).

In this paper, I suggest that a significant aspect of the dominant discourse of organizations and management today is the discourse of constant change. This discourse operates as a grand narrative and requires managers and others in organizations to be enterprising, flexible, change champions, and so on (Campbell Jones and Grice, 1999). In interrogating the written narratives of managers it is possible to identify the influence of this discourse on managerial identity in ways that reflect how a manager accepts or rejects this requirement to be "for change." In addition it is also possible, using analytical tools derived from Bakhtin (1981, 1984, 1995a, b), to appreciate how managers reject (or accept) alternative identities to this discourse of constant change and of what it is to "be" a manager in the contemporary world, particularly in how they voice others in their narratives. In the following section, therefore, we outline key concepts in Bakhtin's (1981, $1984,1995 \mathrm{a}, \mathrm{b})$ thought as it applies to the interpretation of text and discourse (Wortham, 2001 ), before using these concepts and tools in the interpretation of three narratives written by managers. This is followed by a discussion.

\section{Managerial identity and Bakhtin's dialogical approach}

What purposes do people have when they construct a written or verbal narrative? This is an enduring question in narrative analysis regardless of the perspective/genre from which one attempts to interpret narratives (Boje, 2001; Czarniawska, 2004). Polkinghorne $(1988$, p. 1), for example, argues that narrative is an important way through which human experience is made meaningful. Bruner (1990, p. 121) suggests that the self-acting as narrator not only recounts but justifies actions. This idea of self-justification in narrative is developed empirically by Baumeister and Newman (1994) who propose that stories are told to indicate the worth, efficacy, morality, and purposefulness of the narrator. Sarup (1996, p. 16) argues that our story "does not unfold; to some extent we construct our story, and hence our identity." Wortham (2001, p. 1) suggests that sometimes narrators can partly change who they are by telling stories about themselves. Narrators may in some ways seek to "explain vicissitudes in the drama of interpreted lives, including time, truth, beauty, character, and conflict" (Dauite and Lightfoot, 2004, p. x). They may tell stories for restorative purposes, seeking to manage the stress of contemporary organizational life (McKenna and Richardson, 2003). Narrators develop plots and engage in emplotment through which they may hide, or indeed make visible, the purpose of their narration (Czarniawska, 2004). Narratives are also ways through which people express emotions and feelings about their lives, including their organizational lives, and take the opportunity to be reflexive (Boudens, 2005; McKenna, 2007). Narrators may also wish to elicit a particular kind of response from the reader or hearer (Engel, 2000), perhaps of support, sympathy, collusion, etc. Gabriel $(2000$, p. 36$)$ proposes that narrators use a set of mechanisms through which an "underlying set of meanings is generated." He identifies these as 
poetic tropes. A story can be a vehicle through which narrators attribute motives, causal connections, blame and credit, unity, fixed qualities, emotion, agency, and providential significance.

The contribution of this paper is that it emphasizes not only the representational functions of narrative but also its interactional functions. Through narratives individuals positions themselves against alternative identities. The paper provides a critical reading of narratives written by managers based on the work of Bakhtin (1981, 1984, 1995a, b) and Wortham's (2001) development of these ideas. Bakhtin's (1981, 1984, 1995a, b) work is important in this regard, pointing us in the direction of the interactional positioning that is implicit in narrative. Thus, when a person writes (or speaks) it is not only the content of the written words that are important, but how those words position the narrator, others in the story, and the event(s) themselves in a wider structural and discursive context.

The interactional positioning undertaken in a narrative is related to the utterances made by the narrator as he/she narrates him/herself and others in the narrative. To understand an utterance it "is necessary to understand the meaning of the utterance, the content of the act, and its historical reality, and to do so, moreover, in their concrete inner unity" (Bakhtin and Medvedev, 1995, p. 149). In other words, aspects of a narrative need to be understood as to how they reflect the voices of the narrator, of others and of society. A narrator is connecting often diverse discourses together through a dialogue within the narrative. In analyzing narratives, we can investigate how particular utterances position writers in specific ways relative to others and to society (Wortham, 2001). Such an investigation also enables a consideration of the interplay of discourses as they are reflected in the narration and as they reflect the identity and identification of the author.

To know, however, the interactional positioning and identification a narrator takes it is necessary to know something of the time and place when the narrative was constructed (Holquist, 2004). Identity is formulated within a specific location, and that location may be dominated by a prevailing regime of truth that shapes how a particular person should "think" and "be" in that location and at that time. A dialogic approach used critically to interrogate managerial narratives helps to uncover the identity within a narrative adopted by the narrator, and those identities that are marginalized and/or ignored. For example, if a manager writes "during the change 300 staff were downsized" a monologic approach would focus on the content and that "downsized" means dismissed. A dialogic approach, however, would begin to position the writer in a broader context. For example, how is the phrase written? Does the narrator imply that "downsizing" is inevitable, natural, normal, acceptable? Do they position themselves against others who oppose "downsizing", i.e. communities, trade unions etc? Therefore, the meaning in a narrative, and particularly the utterances that constitute the narrative, enter an already existing world that helps us to make sense of the narrative more fully, and helps us to locate it within competing discourses. Moreover, using a dialogic approach enables the interactional positioning of the narrator to be more firmly established.

Wortham (2001, p. 21) distinguishes between the storytelling event and the narrated event in narrative. The storytelling event (the dialogue) is the interactional context, where the narrator is positioning themselves in a broader context through what they write. The narrated event (the monologue) is what is described in the narrative. In order to develop an interpretation of narratives various aspects of the storytelling 
event must be taken into account because it is here that the broader context, including the interplay of discourses within the narrative, is understood. What is present in the narrative goes beyond what is described. Narratives are polyphonic, that is they are multivoiced:

[...] people cannot interpret represented or narrated content alone. Interpretation of an utterance also requires construal of a second interactional level, because the words used in any utterance have been spoken by others.

When a manager writes about events, they immediately open a dialogue within which they are an active participant in shaping/positioning their identity and the identities of others within a wider discourse. These identities are relevant to a particular place and time in relation to the discourses that are available about what a manager should "be." However, what a manager should "be" at a particular place and time can only be understood against other identities that are rejected; that is, dialogically. Following Bakhtin (1995b, p. 161), a manager's "consciousness of self" in written narratives is "constantly perceived against the background of the other's consciousness of him." The "other" being both within the narrative, constructed by the narrator, and beyond the text - the discourse that partly shapes the dialogue in the text. A narrator then is always writing with a sideward glance at the discourse outside of the immediate event(s) being narrated. In short, when a manager writes they are describing events, positioning themselves and others within the narrative interactionally, and placing all in relation to the social world and the discourses that shape it.

When managers write about events in their organizational lives their narrative enters an existing grand narrative/discourse (Alvesson and Karreman, 2000) that partly shapes the managers' narratives and the position of the manager within it. In turn, the managers' narratives contribute to, challenge or perpetuate the grand narrative. Managers are voicing themselves from a unique position in life but that position is relational to something other (Holquist, 2004). In the following section, we consider Bakhtinian concepts as operationalized by Wortham (2001) that can help to understand how managers position themselves within a wider discourse and, how their positioning is subject to the constraints of available discourses in such a way that they are sometimes called to have a particular managerial identity.

\section{Mediation, voicing, and ventriloquation}

Mediation is a concept that applies to something that enables an understanding of the interactional positioning that aspects of a narrative achieve (Wortham, 2001). In sociology, particularly the work of ethnomethodologists and in the work of linguistic anthropologists, the concepts of indexicality and contextualization cues reflect this mediating step (Garfinkel, 1967; Gumperz, 1982; Mertz, 1994). In other words, when we read a managerial narrative some aspects of it will indicate how its context should be construed. However, in order to recognize this it is important to know something about the way we as the reader and the narrator are addressed by the world and, how the narrator constructs an identity through the way they position themselves in the narrative.

Following Wortham (2001), two questions are important in applying mediation to managerial narratives. First, in a written narrative, what cues make aspects of the narrative salient, and second, how do these cues and salient contextual features create 
the interactional positioning being accomplished in the narrative? For Bakhtin (1981, $1984,1995 \mathrm{a}, \mathrm{b}$ ) an important answer to this question was through the concept of voice (Holquist, 2004). Essentially, a narrator gives voice to characters in the narrative including him/herself. So, the narrator positions him/herself in relation to others in the narrative and in relation to a wider discourse. Narrators also give voice(s) to other characters and the broader set of discourses within which narratives are located.

The concept of voicing is important in that it reflects how a narrative represents polyphony or multivocality through the many voices in the narrative. The narrator is not simply writing as an individual, they also voice the utterances and discourses of other groups and institutions and interests. Furthermore, these voices are a particular instance of the "larger polyphony of social and discursive forces which Bakhtin calls "heteroglossia" (Holquist, 2004, p. 69). Within managerial narratives, therefore, we might be able to read for multivocality and identify what discourse is privileged from those which are marginalized, peripheralized, and unacceptable discourses that shape what a managerial identity should be in the contemporary organization. These voices/identities might be ones that narrators give themselves, give to others, and/or give to the wider world. For example, managers might privilege the idea and identity of managers as being "for change," being "new," "flexible," "enterprising," "taking responsibility," and might marginalize the identity of a manager who seeks to maintain the status quo, to build loyalty and community, and respect for the past.

Bakhtin (1995b) in his consideration of the novel, argues that novels contain a multiplicity of language and socio-ideological belief systems that are given voice by the narrator. Narrators embody particular points of view about themselves and the world, but these points of view are shaped within the discursive fields and socio-ideological belief systems that prevail. So, for Althusser (2001, p. 115) "all ideology hails or interpellates concrete individuals as concrete subjects, by the functioning of the category of the subject" (original italics). The managerial subject is called, or hailed, to be a particular kind of subject, or to have a particular kind of managerial identity that is relevant to a particular time and place. Foucault's (1995) idea of subjectification and "the discursive 'fixing' of the conditions of subjectivity in particular places and times" (Clegg, 1998, p. 35; Foucault, 1995) directs us to an understanding of how a certain managerial identity is "normalized." Not only is a manager called to have a certain identity, this identity is considered "normal," and therefore, alternatives can be discursively fixed and consequently marginalized as "abnormal," "unacceptable," "outmoded," "pathological," and so on. In the authoring of narratives then, managers construct and enter into a dialogue, not only with other voices, but other possible managerial identities, and other ways of managing and organizing.

A concept related to voicing is ventriloquation. Not only do narrators articulate their own voices in narratives, and thus position themselves in relation to alternative voices, they also articulate alternative voices for themselves and index voices for other characters. This reflects an awareness of potentially conflicting discourses that can drive a managerial identity, meaning that in managerial narratives a narrator may articulate one or more identities for themselves; perhaps as a conforming self, but also as a moral self or a rebellious self (Collinson, 2003; Tappan, 1999). They will also organize or disorganize other characters through ventriloquating others' voices (Bakhtin, 1981). Ventriloquation is the process through which a narrator takes up an identity in the story that unfolds and places it in a discursive and dialogical context. 
Bakhtin's $(1981,1984,1995 \mathrm{a}, \mathrm{b})$ ideas and concepts offer a set of tools that enable a critical evaluation of managerial narratives. In this paper, they are used explicitly within a critical perspective. In doing this, I suggest that an important aspect of the discourse that dominates how to "be" a manager is the discourse of change. From much of the contemporary business literature it seems clear that the theme of change is a central feature of the dominant business and managerial discourse. This has implications for the identity that managers are required to assume; for example, they are required to be flexible, enterprising, and champions of change. These change related "competencies" are often enshrined in sets of competencies that organizations produce for defining the ideal manager/leader (McKenna, 2002, 2004). The significance of the discourse of change for managerial identity is captured in sets of competencies and becomes an ideal by which managers are measured and assessed. Through an investigation of managerial narratives it is possible to identify the prevalence and power of the discourse of change and whether and how managers accept or reject the managerial identity attendant with it.

\section{Methodology: collecting and analyzing narratives}

While there is a great deal of work that has engaged qualitative methods in studying managers' narratives and/or which has adopted a narrative analytical approach to understanding management and organizations, there is relatively little that has used data acquired through extended written narratives of managers (Down and Reveley, 2009; Fronda and Moriceau, 2008; Landau and Drori, 2008; Letiche et al., 2008; Vickers, 2008; Watson, 2009). Indeed, in a literature search for this paper the author found no references for any study that had collected written narratives from practicing managers. In this sense, the data collected and reported in this paper contributes uniquely to the body of literature on narratives and narrative analysis, particularly as it relates to practicing managers.

Over a 15-year period the author has collected narratives from managers describing event(s) in their organizational experiences that they consider to have been significant or memorable for them. This relatively simple guideline was applied to managers on MBA programmes and executive education courses with the purpose of forming the basis for in-class discussions about personal and organizational development and conflict. No rewards were attached to the task and the task never has a grade value attached. As such it was considered that the collected narratives offered an insight into specific experience(s) managers had at a particular moment in time captured in narrative form. Narratives have been collected, not for the explicit purpose of studying managerial identity, yet when investigated emerging themes relating to what a managerial identity could/should be were observed.

The narratives were thus analyzed using NVIVO qualitative analysis software. This involved creating lists of "nodes" representing themes contained in the data. Narratives were uploaded into the NVIVO software and coded in relation to themes relevant to the research questions and around themes emerging through the process of data analysis. The benefits of using NVIVO qualitative analysis software was that it enabled a thematic analysis (King, 1998) of the narratives around three key questions. First, to what extent was it possible to identify how managers accepted/created a managerial identity for themselves that reflected the discourse of change? Second, how did they voice and ventriloquate others, including the wider world in their narratives, 
and was it oppositional to the identity they accepted/created for themselves? Third, what were the key aspects of how they voiced their identity and those of others?

Narrative analysis is a well established qualitative research method and narratives can be analyzed in a variety of ways (Boje, 2001; Clandinin, 2007; Czarniawska, 2004). In this paper, a critical approach is adopted to analyze narratives. It is argued that managers shape an identity for themselves rooted in a process of interactional positioning that they take with respect to a set of available discourses. Often they formulate an identity that is influenced by the discourse of change. This is not to suggest that there cannot be resistance to this "calling" by managers (Collinson, 2003). Indeed, in one of the three case studies investigated in the following sections a manager rejects this identity. Moreover, narratives often reflect a deep ambiguity and conflict about managerial identity among managers.

Using tools derived from Bakhtin (1981, 1984, 1995a, b) and developed by Wortham (2001) extracts from three managerial narratives are used to show how a critical dialogical approach to understanding managerial identity can be undertaken. In this sense, the analysis contributes to the assemblage of methods that can be used to understand the connection between the discourses and the structures within which they operate, and the lived experiences of managers as they think and act within organizational contexts. I deliberately focus on only three narratives in order to show more clearly how a dialogical approach to interpreting managerial narratives might be developed and used with respect to managerial identity.

The names of the authors of the narratives have been changed for confidentiality. In addition, participants on all programmes were informed, where narratives were invited, that the material may be used in presentations and publications after a time lapse of four years from the date of writing. Those who consented to such use were asked to sign an informed consent statement and this applies to the three examples used specifically in this paper.

\section{Narrative 1: Maureen (New Zealand) \\ Context}

The discourse of new public management (NPM) constitutes an important context within which managerial narratives from the public sector are written. NPM has had a considerable impact on global public sector management (Bartlett and Dibben, 2002; Bessant, 1995; Brittan, 1984) and it has been an important driver for changing practices in relation to public administration, management of healthcare and education. NPM has infiltrated thinking about management in the New Zealand health service where there has been increasing pressure to be cost-efficient through the application of corporate style management techniques.

\section{The organizational context}

Maureen works in a small clinic in healthcare:

The organization is the brainchild of a group of women doctors who were working for a variety of healthcare organizations in small city[1] in 1998. One of these women called a meeting of female doctors who were frustrated by having to work within male dominated organizations where they had no power to change the dominant culture, no input into the mission statement and little influence on the structure of these organizations. The common desire of all these professional women was to be able to work within their chosen profession 
in an environment that supported their interests. None wanted full time jobs, all had personal commitments to family and home, and all had extramural activities that they saw as necessary to self-fulfilment.

In this passage, Maureen is narrating events that led up to the establishment of the clinic. We observe that she voices the doctors and the wider context in which their initiative takes place. She positions the female doctors in relation to this wider context. Maureen shapes the identity of the women doctors in the narrative by defining them as a group of feminist doctors whose work world was male dominated and within which they felt powerless. The doctors wanted to take control of their situation to enable them to achieve better work/life balance.

Maureen is also giving voice to a world beyond the clinic. A number of cues in the passage identify an already existing world of male domination and male dominated organizations; of the social and professional exclusion of women from power and involvement and; the inability of organizational structures created by men to take the needs and wants of women into account. Maureen as narrator is not herself indicating that she accepts this view of the social and organizational world. She is ventriloquating that it is the position of the doctors.

Maureen joins the clinic and enters the narrative in 2003. As she begins to narrate events from her position as practice manager her narrative style changes. In narrating the establishment of the clinic Maureen noted how it "challenged the order of things." That is, it was a feminist organization that challenged the medical fraternity in order to establish an alternative idea of a clinic. The principles of the clinic were laid out in its Ground Rules, a set of guidelines indicating how conflict would be resolved, decisions would be made and the organization managed. The Ground Rules emphasized collective decision-making and conflict resolution. As practice manager Maureen positions herself relative to the Ground Rules:

Another unique feature of the organization is the Ground Rules which were drawn up by the partners, based on principle, to guide the decision-making process and to refer to in times of conflict. The Ground Rules still exist in their original format six years after the opening of the business, and have not yet been revisited. Nor has the Mission Statement. No change has been made to the original business plan which was put together to apply for funding. All of these were developed to guide a young business still coming to terms with its environment. Now that they are established, they need to look at these things and assess whether they are still relevant.

In this passage, Maureen gives voice to the current state of the organization. The organization, as embodied in the Ground Rules, mission statement, and business plan is out-dated. It is in need of change because, it is implied, the environment has changed. We note here Maureen's acceptance of the discourse of change and the view that organizations should respond to environmental changes. Matters of principle, which the Ground Rules represent, are negotiable in Maureen's world. They cannot be a constant organizing principle for the clinic in a time of change. The Ground Rules may now no longer be "relevant" and are disposable.

\section{Self and interactional positioning}

As the narrative progresses Maureen's voice enters events more strongly, becoming increasingly juxtaposed with other voices. This builds on Maureen's earlier voicing of the organization as "feminist" and being out-dated. She begins to connect the feminist 
nature of the organization to organizational ineffectiveness and positions her "self" in this context:

The practice needed to recruit an accountant [...] it was a long drawn out affair in which the better qualified male was overlooked in favour of a less able female because of the strong promotion by the lesbian partner. I believe that at this point we must stop using the term "team" in conjunction with the organization. From my perception of what happened, a division occurred because those who had not been able to promote their chosen candidate felt manipulated, and power politics began to takeover as the dominant frame in the organization. However, the perpetuation of the myth of the "feminist" organization was tacitly acknowledged as more important. Because the feminist culture implied that "women working together should be able to resolve these differences," the issue became a taboo subject and the feminist culture started to become a prison.

There are several mediators in this passage that position Maureen interactionally relative to the organization and other members of the organization. She ventriloquates the organization as becoming a feminist prison caught up in an ideal way of doing things. Instead of operating on meritocratic principles members of the organization engaged in power politics and manipulation in the appointment of an accountant that reflected a deeper organizational malaise. The culture of the clinic restricts its ability to change. While a monologic approach to the narrative would emphasize the culture change aspect, a dialogical approach highlights how Maureen voices herself and the "others" that indicates a more insightful interpretation of the discourses involved as they are narrated by Maureen.

Furthermore, there is a sense that she sees the lesbian partner in the clinic as instrumental in perpetuating the "prison." In voicing and ventriloquating those in the organization and the organization itself, Maureen discursively fixes herself in opposition to this type of organization. She is essentially saying to the reader that this is not what this organization needs to be, it must change, and that Maureen herself is opposed to a "feminist" organization. This "prison" is not a viable alternative to the necessary changes required to make the clinic more efficient and effective. At the level of managerial identity we can read Maureen's positioning; as Wortham (2001, p. 138) notes "we are to some degree the kind of people we position ourselves as when we narrate ourselves." In positioning herself interactionally in her narrative Maureen emphasizes her attempts to change the clinic:

I decided to make a small change to the way things were done, little realising the butterfly effect of what I saw as a logical solution to the problems I had encountered in "learning" the tasks. I documented the tasks as I had been told to perform them, and then gave them to the receptionist for her to approve. After all she was the "authoritative source." What I did not realise was that I was in fact diminishing her power within the organisation, because as long as everyone had to refer to her with regard to instructions, she held the key. However, I sold it to the partners as a demystification process, and a receptionist's procedure manual was written, and has become a key tool.

I was not deliberately initiating change to change the balance of power. I felt genuinely unable to operate in such an unstructured way, when the processes required were very structured. What I was doing was to give some sort of order to the organisation, which seemed to me to be logical and rational, trying to gain some sort of balance between personal power and organisational empowerment. I think that I was imposing a mechanistic order on a politicised situation. I must say that the systems that I put in place improved the bottem line for the organisation. 
The order and structure was needed, because the dominant culture had changed from being one of synergy, excitement and teamwork, to being one of power and dominantion within the organisation. People had become separated from each other, and the partners had begun to operate more as a group of individuals working together under the same roof. Their desire to see themselves as a feminist organisation had become more important than the need to recognise that they were no longer working as a team. They were trapped in a prison perpetuating the myth of a "feminist" organisation. They and the organisation had become rigid and inflexible.

In each of these passages Maureen is positioning herself and others, including the organization, through double-voicing and ventriloquation. In the first passage she voices herself as a logical, procedurally driven person, putting in place systems for the better management of the clinic. However, she juxtaposes this against the voice of the receptionist, the "authoritative source." Until there was a procedural manual power over the way work was done resided with the receptionist. Not only this, but how things were done was a mystery to all in the clinic, as a consequence the development of a manual opened up the work process to the partners. We also observe how Maureen positions herself relative to the receptionist. The cues from the passage suggest she was somewhat contemptuous of the receptionist and possibly of the power and control she had over how work was done in the clinic.

There is beyond this voicing and double-voicing a broader context: the context and discourse of rational processes for the conduct of work juxtaposed against political processes. Maureen speaks with the voice of the professional manager against the voice of the unprofessionally managed organization, represented by the receptionist. Maureen is occupying a "particular position within the larger society" (Wortham, 2001, p. 39). Her words are "shot through with intentions and accents [...]. All words have the 'taste' of a profession, a genre, a tendency, a party, a particular work, a particular person" (Bakhtin, 1981, p. 293).

Maureen's interactional positioning of herself in this wider context and discourse is pursued in the second passage. She clearly adopts a "particular point of view on the world" and about her "self." She believes that structure, order, logic, and rationality are necessary in the clinic. Her initiatives become key tools and improve the "bottom line" of the organization. She voices who she is from a clear position, and this voice "invokes positions and ideologies from the larger social world" (Wortham, 2001, p. 40). This theme is continued in the third passage where Maureen juxtaposes order and structure and the need for change, against an inflexible and rigid "feminist" organization dominated by individuals concerned with power and domination. Social positions are established with the narrator, Maureen, clearly standing on one side speaking with the voice of a professional manager. On the other side are those referenced as "feminists" and Maureen is taking "an evaluative stance with respect to them" (Wortham, 2001, p. 71), for example, that they were concerned only with domination and power.

Figure 1 shows the monologic and dialogic aspects of Maureen's narrative. In a monologic discourse "the social position of the speaker is irrelevant to its meaning" (Wortham, 2001, p. 18). However, a dialogic approach emphasizes how a dialogue develops within the narrative, as if a narrator was entering into a dialogue with other people and as a consequence of that, with other ideas, concepts, and ways of acting. At a simple level Maureen's narrative is about the difficulties she experienced in making changes in an organization. A dialogic account, however, would consider the 
Figure 1.

Maureen's narrative and discourses
Dialogic discourse

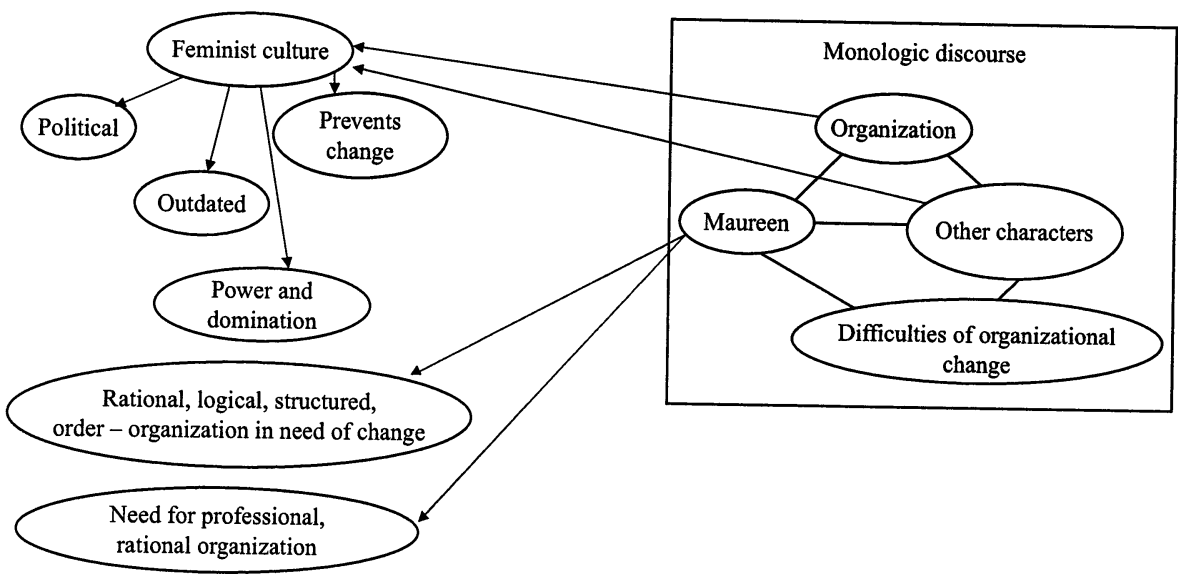

interactional positioning of the narrator in relation to all of the voices the narrator raises in the narrative. Moreover, all of these voices have a social as well as discursive existence beyond the narrative itself.

\section{Narrative 2: Colin (Canada) \\ Context}

Colin's narrative concerns a small engineering company Engco[1]. In the introduction to his narrative Colin describes a changing environment within which Engco has to compete; a situation of global restructuring and increased global competition within a deregulated market for steel products. In response:

Engco senior management had restructured the company into four separate divisions dealing with fabrication and design, machining, casting and sheetmetal production. These changes, however, had no significant impact on company performance and Engco continued in severe trouble.

Monologically Colin describes problems with company restructuring, however, a dialogical reading indicates cues that suggest a particular voicing of senior management. In another passage in the introduction Colin continues to voice senior management in this way:

I felt that senior management, many of whom had been at Engco for many years, had little idea as to how to change the business in any real way. They played with the structures but were afraid to take any of the hard and necessary decisions that were required. They could not get past the kind of view of the business as a family club.

In this passage, Colin is continuing to establish himself in relation to the voices he gives senior management and the organization. He associates length of service at Engco with having few ideas as to how to change the business for the better, implying that a new perspective was required. He further associates this to a certain weakness with regard to taking hard decisions and that this might be because senior 
management regard the business as a family. Engco was family-owned and, as Colin indicates, had a paternalistic attitude towards staff:

Senior management treated staff as their children, many had worked at Engco for years, but this was not good for performance. Workers were sheltered from the realities of the marketplace by senior management who wanted to play "happy families."

Colin is establishing himself in opposition to the idea of paternalism which he implies is the current culture of the organization and influences deeply how business issues are dealt with. The idea of an organization based on principles of paternalism, looking after workers and building a "family" is out-dated. It negatively affects performance and shelters everyone from the "realities" of the business environment. Colin is setting up one belief system and discourse against another. In Wortham's (2001, p. 74) terms Colin is using the cue of evaluative indexing whereby he is not only indexing "particular voices but also position(ing) the narrator with respect to these voices." We can see:

[...] this interaction, this dialogic tension between two languages and two belief systems [that] permits authorial intentions to be realized in such a way that we can acutely sense their presence at every point in the work (Bakhtin, 1981, p. 314).

\section{Self and interactional positioning}

After a general introduction to the organization Colin inserts himself more directly into the narrative as it progresses. He has voiced the organization as paternalistic, outdated, and somewhat inflexible. However, now, in a way similar to that of Maureen he voices himself as a kind of saviour of the organization who is able to see what is required in order that it might succeed:

I joined Engco in May 2001 as a technical/managerial assistant. By March 2002 there was a severe downturn in work and the future of the plant was obviously in doubt. I was approached by the Managing Director and asked if I would like to take a more active role by becoming production manager. Instead I insisted that I become General Manager of the whole division under the condition that some long serving staff must leave, as they didn't fit into my plans for the new Engco Sheetmetal division.

Colin voices himself here as the "chosen one"; chosen in this instance by the Managing Director of Engco. What is also important is how he positions himself interactionally against the voices of the "others" in his narrative. He is assertive, with clear ideas about what needs to be done and little concern about asking long-serving staff to leave. He rejects paternalism and loyalty. He portrays himself as a "can-do" individual, a heroic enterprising figure (du Gay, 2004). Colin's "self" is juxtaposed against the voices he ventriloquates for the organization and senior management. In particular, the discourse of change prevails:

My role would be one of managing change. From my time on the shopfloor I could see duplication and inefficiencies surrounding me. There were too many staff for the production requirements, and the administration staff were an obstacle to change. The best way of achieving the changes necessary was through the use of hierarchical authority, as far as I was concerned Engco needed rapid transformation. Senior management had restructured but constrained the divisions to trade with each other, regardless of quality and cost. They had a problem of too much loyalty and commitment, and too much involvement of the family in the business. They needed new and flexible ways because the old ways don't work, and they needed new and flexible people. 
Rigid outdated thinking is holding the company back. Senior management had traditional thinking.

In these passages Colin juxtaposes a number of voices, again not only representing the voice of senior management but also of discourses beyond the text. He operates within the discourse of rationality, efficiency and change and in doing so adopts his social position. Colin also gives us a cue as to his management style when he emphasizes that hierarchical authority is necessary to make the changes. In voicing himself in this way Colin voices others both explicitly and implicitly. The clash of discourses about how to manage the organization is played out in the narrative: rigidity against flexibility; loyalty and commitment against more transactional, efficiency oriented relationships; old against the new; paternalism against autonomy (everyone for themselves). There is a clear dialogic tension between two belief systems. Any positive points concerning the alternative ways of operating are ignored, for Colin not only are they outdated, they are to some extent the continuing cause of the problems at Engco:

It is still a struggle to change things at Engco. It is an "old boys club" and any movement for change seems to get blocked somewhere, and often it is difficult to know where this is. Engco needs to change dramatically because it is inefficient and is managed according to principles that don't fit the world today, it is not possible to be loyal and successful when the world is changing.

Sennett (2007) identifies low institutional loyalty as a social deficit in today's world. Relationships are less important now than mere transactions and "loyalty is dead, and each vigorous employee ought to behave like an entrepreneur" (Sennett, 2007, p. 65). Colin subscribes to this discourse, he is an enterprising self (du Gay, 1994, 2004), a captain of the new capitalism and of "liquid modernity" (Bauman, 2000), taking the necessary personal shape and identity for this time and giving it voice in his narrative. In Figure 2, I identify the monologic and dialogic discourses contained in Colin's narrative. He, like Maureen, carries the identity of a modern professional manager.

Figure 2.

Colin's narrative and

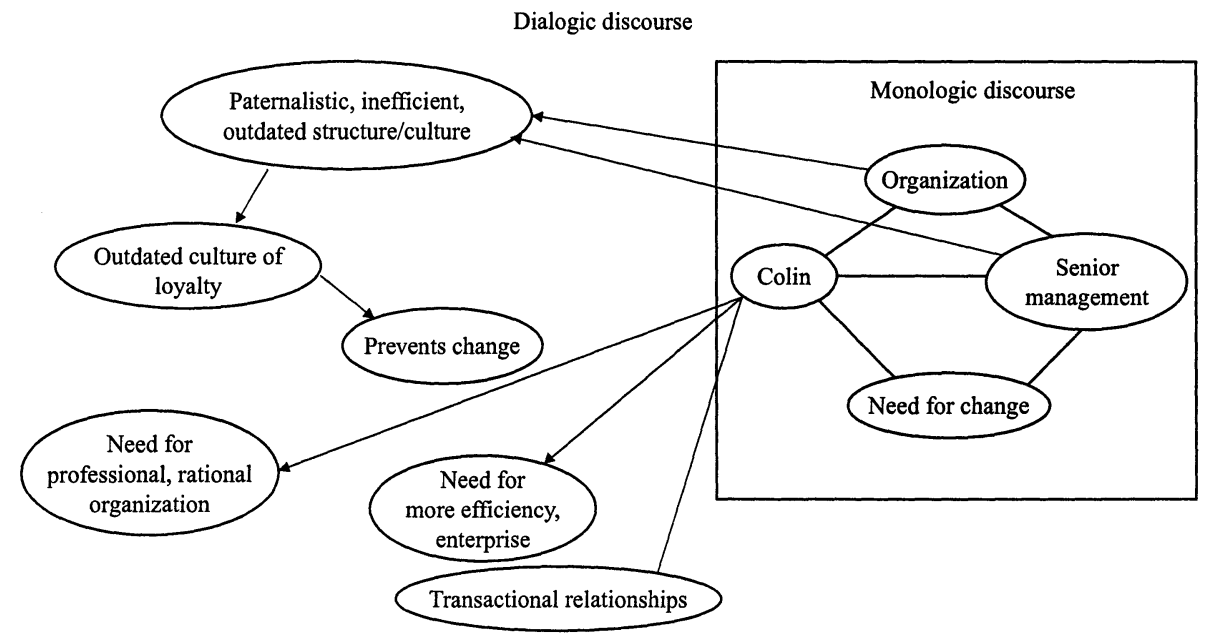

discourses 


\section{Narrative 3: Cameron (Australia) Context}

City management is under pressure. Fiefdoms prevail, protecting inefficiency and duplication. There is pressure from government to save money and to do more things with less. Change is inevitable and my role was to be a champion of change.

And so begins Cameron's narrative indicating that city government is under pressure from NPM initiatives that challenge the current management of city government. In this opening passage Cameron acknowledges acceptance of the discourse of change and voices his role within it. Simultaneously he voices others; those who create fiefdoms and protect inefficiency and duplication. Cameron is interactionally positioning himself relative to the other voices; as Sarup (1996, p. 47) notes "identity is only conceivable in and through difference."

\section{Constructing the organizational reality}

I freely acknowledge full buy into the incompetence, self-interest and manipulation that are still going on in the organization. I used these excuses and tools in a flexible way to further my own cause and ensure that the world as I see it prevails. I intended to win. Not only would the organization need to change, I was going to change it my way.

Unlike Maureen and Colin, Cameron enters his narrative in a much more self-interested way. While Maureen and Colin develop a "hero's narrative" as saviours of their respective organizations, Cameron is initially concerned with his "own cause." He opens up a dialogue with the organizational world that voices it as more political than rational. He also positions himself as willing to be political within it. As Bakhtin (1984, p. 193) notes, the voice of a narrator can sometimes "clash hostilely with its primordial host and forces him to serve directly opposite aims."

Although Cameron voices change as inevitable, the direction of change is dependent upon the power of those involved. This is similar to Colin who highlighted the need for power to make necessary change. Cameron voices himself as a self-interested change agent who needs to be enterprising and to acquire power in order to make the changes that he wants. He was prepared to "be" a certain way in order to pursue this agenda, adopting a political identity in order to facilitate change. Cameron is offering the reader his internal conversations (Archer, 2000) regarding how he intended to present his "self" to the organization:

The city was run by powerful Area Managers who had managed to create fiefdoms and generate cult followings among their staff. This needed to end. There was inconsistency in service provision, poor customer service, duplication of processes. It appeared to me to be a simple solution to what I saw was wrong with the organisation. The identified drivers for change rang true to me. These changes would suppress the egos and allow us to serve the public in a manner that would see perceptions of the lazy city employee forever buried. I wanted to play whatever part I could in order to reshape the dysfunctional and self-serving environment.

Here, Cameron enters into a dialogue as narrator and as participant with his voicing of the way city government currently operates. He voices and articulates the area managers' power and connects it with the inefficiency of city government. This is the dialogic foundation against which he presents his own voice and social position. 
He presents his position in the narrative as a partly moral one. It seems clear that we might infer from the narrative how Cameron regards what he is doing as the right thing to do, and the area managers and their cult followers are the opposition serving to give city government a bad name with the public. Cameron references the area managers as cult leaders that create dysfunctional and self-serving environments. He is evaluative towards them as the basis for establishing his own position in the narrative. It is also interesting to note the language he uses to define and articulate area managers - they have created fiefdoms and generate cult followings - which is indicative of positioning the area managers and certain followers as outdated, medieval and non-rational in their thinking and action. Cameron implies that he will be a saviour "acting within his own belief system" (Bakhtin, 1981 p. 334) while in fact, he is representing a discourse of change, rationality and efficiency that has operated to call him to this task.

\section{Self and interactional positioning}

Cameron continues to voice the moral dualism introduced in the earlier part of his narrative. As his narrative proceeds he focuses more on the details of his action to change the organization:

I was in a war with losers and clueless technocrats. The battle with these people was to be in the ascendancy in your department and in the organization. I would fight them in a different fashion. The environment would not have seen the battle fought that way before and therefore had no strategy to combat my tactics. Those who would resist would be put to the sword. It was a case of the past or the future.

Here, Cameron does not represent himself explicitly but interactionally positions himself with respect to others. Cameron is contemptuous of the "technocrats" with whom he works and believes that his obligation is to engage them in a war reflecting the battle between the modern and the non-modern ways of managing organizations. He has indexed the organization and certain people within it, and established a position for himself relative to it. As with the narratives of Maureen and Colin, a key element of Cameron's narrative is the confrontation between the "old" and the "new," the past and the future.

The depth of his passionate commitment to change, reflected in the preceeding passage, is further evidenced in Cameron's descriptions of how he waged war on his adversaries. However, as his narrative develops Cameron begins to highlight the dirty political work that is part of the process of organizational change:

My first day my new manager, $T$, had a uniform ready for me to wear. I politely refused and we reviewed the reasons I was appointed. It was obvious that the decision to establish the role was not one that $T$ wanted. Indeed the role she had in mind was one of operations management. To my horror I found myself thrust into managing parking operations for the city. Psychological contracts my arse! This was a pathological manager ensuring immediate dominance over me and distancing herself from the chaos I was about to find. That chaos had a name. It was parking. This was the leper of the organization. No one like a parking officer.

But I befriended parking officers. I was one of them, an untouchable to members of the public. With the management team I used facts, refused to listen to emotion, delivered on time and under budget. I auctioned the requests of my staff quicker than God. 
Six months into my role at parking things changed. I discovered my boss, T, was sleeping with my Head of Department. They were lovers. She was divorced and he married. It was the unspoken scandal. I finally had a way to win. $T$ was promoted into obscurity, but just when I thought I had won I found out I had lost. I became her replacement. Then four months later the organisation decided to restructure.

At this point I would like to re-state my role with the organisation at this time. I was the parking operations manager; acting parking services divisional manager; manager of business development; human resource manager traffic and parking services; acting head of department, traffic and parking services; acting group manager, traffic and roading services. Each of these roles required specific actions and responses on my behalf. For example, meetings were being held for old department heads where a message about the change was given, that would be immediately followed by a meeting for the new Group Managers where the same message was completely different. I was so busy at no stage did it ever occur to me neither to ask for help nor to seek any. None was ever offered. Finally it was Christmas.

Deconstructing managerial narratives using concepts derived from Bakhtin facilitates an appreciation of how much more powerful analyzing the interactional positioning taken by the author is than a mere representation of that position. For example, representing "T" as "pathological" invites us to accept Cameron as "normal" and functional. Mere description of the issues with parking operations would have offered a monologic view of the problems Cameron faced. Through an awareness of where "the speaker is placing herself interactionally with respect to members of those other groups" (Wortham, 2001, p. 19), an analysis can accomplish more socially and organizationally consequential understanding. For example, in the first paragraph above Cameron connects his voicing of " $\mathrm{T}$ " as pathological to her desire to dominate him and distance herself from blame for the problems of parking operations. Not only is it possible to appreciate how the narrator positions the voices, as reader we can sense more the political swamp of the context.

What is also indexed in the first paragraph above is a change in Cameron's narrative from voicing himself as a heroic change agent, to a sense that he is becoming increasingly sucked into the chaos of the organization. His language is less one of "battles" and "war" and a conflict of good against evil, right versus wrong and future versus past, and more a language of sickness, dysfunction, pathology, and chaos. He associates himself now with the "untouchables" (paragraph 2). Acting rationally with his management peers but befriending his staff, Cameron "arranges these voices in some configuration and positions [his] narrated self with respect to those salient voices and their associated ideological commitments" (Wortham, 2001, p. 154).

Ultimately, however, Cameron's voice shifts from the heroic lion heart ready to take on the organization, its fiefdoms and cults, to the voice of an overworked and disillusioned manager. Whereas both Maureen and Colin end their narratives believing still in the importance and value of the discourse of rational change in their respective organizations, and thus maintaining the identity of the rational, professional manager, for Cameron his experiences lead him to a different conclusion. The organizational experiences of the heroic, master of the universe voiced at the beginning of the narrative, transform him into a physically sick and emotionally and professionally disillusioned person. He ultimately rejects the call to "be" a particular kind of manager:

SICK. On December 26 whilst sitting in the sun on our lawn I felt sharp pains from within my gut. Within three days I had been rushed to hospital suffering from severe dehydration 
and loss of blood. My immune system had stopped functioning and I was seriously ill. Within the week my body weight had dropped from $98 \mathrm{kgs}$ to 85 . The only relief was morphine for the pain. I realised that the nonsense was crazy. I wanted to be the last man standing, but in the end realised that this was a lonely and worthless place to be.

Figure 3 shows the monologic and dialogic discourses present in Cameron's narrative.

\section{Discussion}

This paper has sought to show the value of the ideas of Bakhtin (1981, 1984, 1995a, b), and the application of analytical tools derived from his work (Wortham, 2001), to an understanding of managerial identity. Through an analysis of three narratives written by managers a critical dialogical approach has been adopted to investigate how managers (re)present an identity. What is of importance, however, is not the mere (re)presentation of a managerial identity, but how managers do this through interactional positioning in their narratives. Through the creation of a dialogue with "others" in the narratives, managers adopt a social and organizational position that reflects a particular managerial identity. The paper suggests that this identity is partly shaped by a dominant discourse that normalizes what it is that a manager should be in the twenty-first century. Managers are, in effect, hailed or called, to be a certain way: enterprising, "can-do," champions of change, flexible, efficiency-oriented, and so on. Within narratives managers (re)present (voice) themselves and organizations in this way and dialogically reject alternatives, for example, Maureen rejected the idea of a "feminist" organization, Colin rejected a paternalistic organization that emphasized loyalty and commitment to employees. Cameron rejected the organization as medieval

Figure 3.

Cameron's narrative and discourses
Dialogic discourse

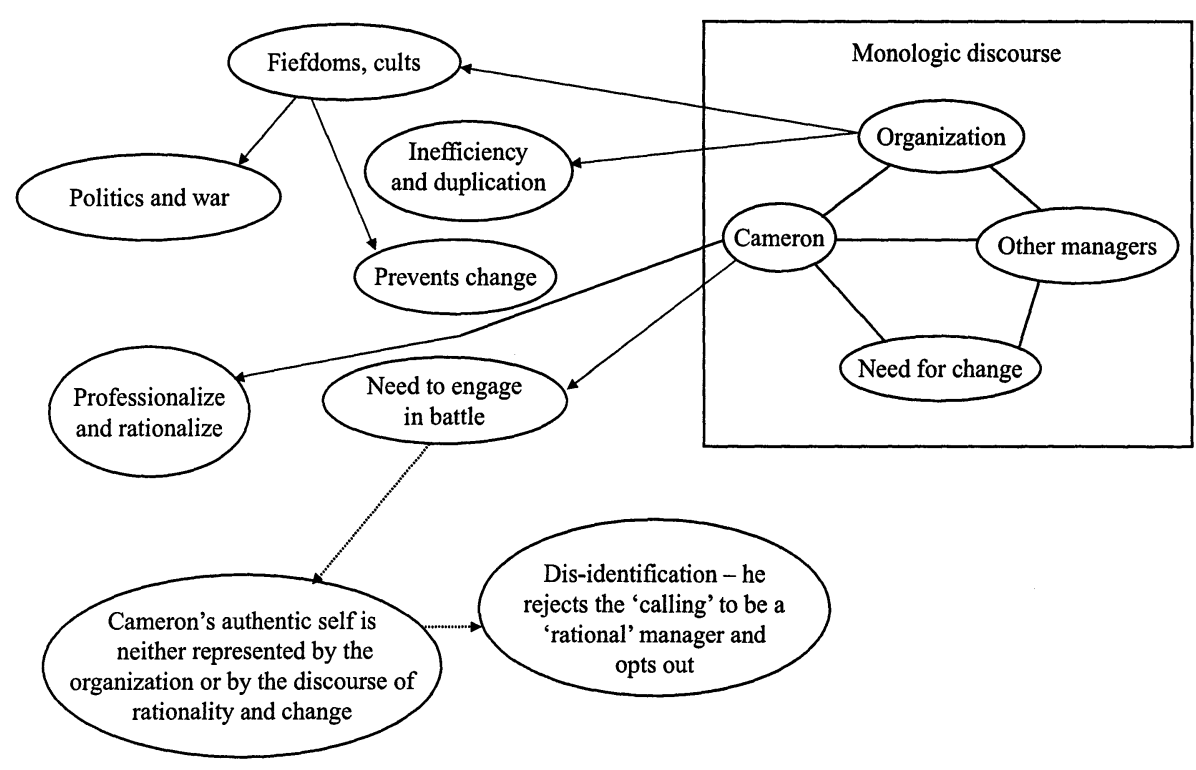


fiefdoms and cults. Not all alternatives rejected are necessarily positive, but within the narratives investigated here alternatives are marginalized as inefficient, outdated, and irrelevant.

The paper contributes to the debate concerning managerial identity and highlights how "identities are, to some extent, constructed by social structures" (Sarup, 1996, p. 40) and the discourses which accompany them. Yet through "free will' - the processes of choice in interpretation, selection - we can, to some extent, limit or adapt the external determinations" (Sarup, 1996, p. 48). Using dialogical tools for the analysis of narratives we can appreciate how managers are partly driven by a dominant business discourse (of change), but also how they may reject it (as does Cameron). It is possible to identify through a critical dialogical approach towards managerial narratives, the relationship between the impact of a powerful discourse and its role in determining the thoughts and actions of managers. Moreover, it is also possible to identify how some managers reject the "calling" of a particular discourse through their experiences of managing and organizational life. While managerial identity - who am I? How should I act? - are questions partly shaped by a dominant discourse that normalizes a way of "being" a manager, the identity can be shaped, (re)created and rejected by the manager him or herself within these constraints.

Future research might investigate, through a range of qualitative methods, the relationship between a dominant discourse of managerial identity and managerial experience of and response to this identity (Alvesson and Karreman, 2000). There is an increasing amount of work that investigates such matters both conceptually and empirically. In particular, the idea of dis-identification is important in understanding how managers and all employees might be concerned with constructing more authentic identities at work (Costas and Fleming, 2009). In this sense managers and others might become more aware as to how their putative "real" identity may in fact, be entirely unreal. However, notwithstanding the increase in research, the use of narratives written by managers as a source of data to investigate the relationship between a discourse and managerial identity is rare. Once narratives have been collected a critical dialogical approach to interpretation is one way of analyzing the data and exploring managerial identity in new ways.

The written narratives of managers present windows into organizational events that give rise to practical implications. What is an interesting feature of the narratives reported in this paper, and of the narratives collected in total, is the consistency with which they reflect the discourse of managing and management as concerned with change, being new and modern, being more efficient, ridding the organization of "deadwood," building enterprise and being flexible, and so on. In addition, alternatives are voiced dialogically in the negative. Alternative forms of organizing and managing are considered outdated, inefficient, lacking in enterprise, too compassionate, reflecting a commitment to loyalty that is no longer perceived as relevant. A dialogical analysis of the written narratives of managers offers an understanding of how a particular managerial identity excludes consideration of alternative managerial identities and, in some cases, alternative ways of organizing. The power of a dominant discourse lies in its ability to produce particular kinds of subjects and normalize a specific type of identity, and to marginalize alternatives. Creating alternative ways of managing and organizing under such discursive and material conditions becomes very difficult.

Czarniawska (2004, p. 7) notes that what: 
[...] is considered a vice in science - openness to competing interpretations - is a virtue in narrative. This openness means that the same set of events can be organized around different plots.

In this paper, a dialogical approach has been adopted to interrogate narratives written by managers in order to illuminate managerial identity in relation to a grand discourse/narrative. This interpretation is merely one of many forms of deconstruction that could have been adopted (Boje, 2001). It errs perhaps on the side of determinism rather than voluntarism or constructivism, in that I have offered the suggestion that managers are the products of the dominant discourse of their times, at least in part. I have sought less to discover the intentions of narrators (a subjectivist interpretation), or to interpret the relationship between the narrator and me, as reader and interpreter of the text (a constructivist interpretation) (Czarniawska, 2004). Despite this I hope the use of Bakhtin's ideas provides a further interesting way of analyzing the written narratives of managers.

\section{Note}

1. A pseudonym.

\section{References}

Althusser, L. (2001), Lenin and Philosophy and Other Essays, New York University Press, New York, NY.

Alvesson, M. and Karreman, D. (2000), "Varieties of discourse: on the study of organizations through discourse analysis", Human Relations, Vol. 53 No. 9, pp. 1125-49.

Alvesson, M. and Willmott, H. (1996), Making Sense of Management: A Critical Introduction, Sage, London.

Alvesson, M. and Willmott, H. (2002), "Identity regulation as organizational control: producing the appropriate individual", Journal of Management Studies, Vol. 35 No. 5, pp. 619-44.

Alvesson, M., Ashcraft, K.L. and Thomas, R. (2008), "Identity matters: reflections on the construction of identity scholarship in organization studies", Organization, Vol. 15 No. 1 , pp. 5-26.

Archer, M. (2000), Structure, Agency and the Internal Conversation, Cambridge University Press, Cambridge.

Bakhtin, M.M. (1981), The Dialogic Imagination, University of Texas Press, Austin, TX.

Bakhtin, M.M. (1984), Problems of Dostoevsky's Poetics, University of Minnesota Press, Minneapolis, $\mathrm{MN}$.

Bakhtin, M.M. (1995a), "Heteroglossia in the novel", in Dentith, S. (Ed.), Bakhtinian Thought, Routledge, London.

Bakhtin, M.M. (1995b), "The hero's monologic discourse and narrational discourse in Dostoevsky's short novels", in Dentith, S. (Ed.), Bakhtinian Thought, Routledge, London, pp. 157-94.

Bakhtin, M.M. and Medvedev, P.N. (1995), "Material and device as components of the poetic construction", in Dentith, S. (Ed.), Bakhtinian Thought, Routledge, London.

Bartlett, D. and Dibben, P. (2002), "Public sector innovation and entrepreneurship: case studies from local government", Local Government Studies, Vol. 28 No. 4, pp. 107-21. 
Bauman, Z. (2000), Liquid Modernity, Polity Press, Cambridge.

Baumeister, R.F. and Newman, L.S. (1994), "How stories make sense of personal experience: motives that shape autobiographical narratives", Personality and Psychology Bulletin, Vol. 20 No. 6, pp. 676-90.

Beech, N. (2008), "On the nature of dialogic identity work", Organization, Vol. 15 No. 1, pp. 51-74.

Bessant, B. (1995), "Corporate management and its penetration of university administration and government", Australian Universities Review, Vol. 38 No. 1, pp. 59-62.

Boje, D. (2001), NarrativeMethods for Organizational and Communication Research, Sage, London.

Boudens, C.J. (2005), "The story of work: a narrative analysis of workplace emotion", Organization Studies, Vol. 26 No. 9, pp. 1285-306.

Brittan, S. (1984), "The politics and economics of privatisation", Political Quarterly, Vol. 55 No. 2, pp. 109-28.

Bruner, J. (1990), Acts of Meaning, Harvard University Press, Cambridge.

Clandinin, D.J. (Ed.) (2007), Handbook of Narrative Inquiry, Sage, Thousand Oaks, CA.

Clegg, S. (1998), "Foucault, power and organizations", in McKinlay, A. and Starkey, K. (Eds), Foucault, Management and Organization Theory, Sage, London, pp. 29-48.

Collinson, D.L. (2003), "Identities and insecurities: selves at work", Organization, Vol. 10 No. 3, pp. $527-47$.

Costas, J. and Fleming, P. (2009), "Beyond dis-identification: a discursive approach to self-alienation in contemporary organizations", Human Relations, Vol. 62 No. 3, pp. 353-78.

Czarniawska, B. (2004), Narratives in Social Science Research, Sage, London.

Dauite, C. and Lightfoot, C. (2004), Narrative Analysis, Sage, Thousand Oaks, CA.

Down, S. and Reveley, J. (2009), "Between narration and interaction: situating first line supervisor identity work", Human Relations, Vol. 62 No. 3, pp. 379-401.

du Gay, P. (1994), "Making up managers: bureaucracy, enterprise and the liberal art of separation", British Journal of Sociology, Vol. 45 No. 4, pp. 655-74.

du Gay, P. (2004), “Against 'enterprise' (but not against 'enterprise', for that would make no sense)", Organization, Vol. 11 No. 1, pp. 37-57.

Engel, S. (2000), Context is Everything: The Nature of Memory, W.H. Freeman, New York, NY. Foucault, M. (1995), Discipline and Punish, Vintage Books, New York, NY.

Fronda, Y. and Moriceau, J.-L. (2008), "I am not your hero: change management and culture shocks in a public sector corporation", Journal of Organizational Change Management, Vol. 21 No. 5, pp. 589-609.

Gabriel, Y. (2000), Storytelling in Organizations, Oxford University Press, Oxford.

Garfinkel, H. (1967), Studies in Ethnomethodolgy, Prentice-Hall, Englewood Cliffs, NJ.

Gergen, K.J. (1991), The Saturated Self: Dilemmas of Identity in Contemporary Life, Basic Books, New York, NY.

Gumperz, J. (1982), Discourse Strategies, Cambridge University Press, Cambridge.

Holquist, M. (2004), Dialogism, Routledge, London.

Jones, C. and Grice, S. (1999), "Changing ideology", in Monin, N., Monoin, J. and Walker, R. (Eds), Narratives of Business and Society, Longman, Auckland, pp. 197-208. 
King, N. (1998), "Template analysis", in Cassell, C. (Ed.), Qualitative Methods and Analysis in Organizational Research: A Practical Guide, Sage, London, pp. 14-36.

Landau, D. and Drori, I. (2008), "Narratives as sensemaking accounts: the case of an R\&D laboratory", Journal of Organizational Change Management, Vol. 21 No. 6, pp. 701-20.

Letiche, H., Boeschoten, R. and de Jong, F. (2008), "Workplace learning: narratives and professionalization", Journal of Organizational Change Management, Vol. 21 No. 5, pp. 641-55.

McKenna, S. (2002), "Can knowledge of the characteristics of 'high performers' be generalised?", Journal of Management Development, Vol. 21 No. 8, pp. 680-701.

McKenna, S. (2004), "Predispositions and context in the development of management skills", Journal of Management Development, Vol. 23 No. 7, pp. 664-77.

McKenna, S. (2007), "Deconstructing an 'academic'/'practitioner' narrative through self-reflexivity", Qualitative Research in Organizations and Management: An International Journal, Vol. 2 No. 2, pp. 144-60.

McKenna, S. and Richardson, J. (2003), "Managing in the New Zealand health service: the interpretation of experience", Journal of Health Organization and Management, Vol. 17 No. 2, pp. 74-87.

Mertz, E. (1994), "Legal language: pragmatics, poetics and social power", Annual Review of Anthropology, Vol. 23, pp. 435-55.

Musson, G. and Duberley, J. (2007), "Change, change or be exchanged: the discourse of participation and the manufacture of identity", Journal of Management Studies, Vol. 44 No. 1 , pp. 143-65.

Polkinghorne, D.E. (1988), Narrative Knowing and the Human Sciences, SUNY Press, New York, NY.

Sarup, M. (1996), Identity, Culture and the Postmodern World, Edinburgh University Press, Edinburgh.

Sennett, R. (2007), The Culture of the New Capitalism, Yale University Press, New Haven, CT.

Smith, S. and Watson, J. (2001), Reading Autobiographies, University of Minnesota Press, Minneapolis, MN.

Sveningsson, S. and Alvesson, M. (2003), "The good visions, the bad micro-management and the ugly ambiguity: contradictions of (non)-leadership in a knowledge intensive company", Organization Studies, Vol. 24 No. 6, pp. 961-88.

Tappan, M.A. (1999), "Authoring a moral self: a dialogical perspective", Journal of Constructivist Psychology, Vol. 12, pp. 117-31.

Vickers, D. (2008), "Beyond the hegemonic narrative - a study of managers", Journal of Organizational Change Management, Vol. 21 No. 5, pp. 560-75.

Watson, T.J. (2008), "Managing identity: identity work, personal predicament and structural circumstances", Organization, Vol. 15 No. 1, pp. 121-43.

Watson, T.J. (2009), "Narrative, life story and manager identity: a case study in autobiographical identity work", Human Relations, Vol. 62 No. 3, pp. 425-52.

Wortham, S. (2001), Narratives in Action, Teachers College Press, New York, NY.

\section{Further reading}

Cohen, L. and Musson, G. (2000), "Entrepreneurial identities: reflections from two case studies", Organization, Vol. 7 No. 1, pp. 31-48. 
Holquist, M. and Liapunov, V. (Eds) (1990), Art and Answerability: Early Philosophical Essays by M.M Bakhtin, University of Texas Press, Austin, TX.

\begin{abstract}
About the author
Steve McKenna is an Associate Professor, HRM at York University, Toronto. His research interests include managerial narratives; the independent internationally mobile professional and; the HRM profession and "expertise." He has worked in commerce and academia in Europe, North America, and Asia-Pacific. Steve McKenna can be contacted at: smckenna@yorku.ca
\end{abstract}

